\title{
Research and Development of Shared Restaurant Platform Based on Cloud Computing
}

\author{
Saddam Fuad Hussein Al Qadami \\ School of Business Administration, South China University of Technology, Guangzhou, China \\ Email: saddam_foad_3000@hotmail.com
}

How to cite this paper: Al Qadami, S.F.H. (2018) Research and Development of Shared Restaurant Platform Based on Cloud Computing. American Journal of Industrial and Business Management, 8, 2321-2333.

https://doi.org/10.4236/ajibm.2018.812155

Received: November 14, 2018

Accepted: December 16, 2018

Published: December 19, 2018

Copyright $\odot 2018$ by author and Scientific Research Publishing Inc. This work is licensed under the Creative Commons Attribution International License (CC BY 4.0).

http://creativecommons.org/licenses/by/4.0/

\begin{abstract}
China has entered the stage of excess supply, which provides a material basis for sharing economy. In order to solve the backward management information of the existing catering enterprises, the idle and wasteful problems of human technology, restaurant spaces and food resources, this paper studies and develops a shared restaurant platform based on cloud computing, aiming at overcoming the shortcomings of existing restaurant management, and further integrating and optimizing the food and beverage supply chain resources. Integrating the idea of "sharing economy", this paper proposes a shared restaurant business model, and uses cloud computing to integrate and share software and hardware resources and information to build a shared restaurant platform, through designing three different subsystems of the client, restaurants management background, and platform management background to complete the phased management of shared restaurant platform. Researches develop a shared restaurant platform based on cloud computing, and achieve to make full use of sharing of empty tables, chefs, material, recipes and other resources, provide users with standard, unified and personalized gourmet experience at the same time, and achieve food culture and wealth investment integration.
\end{abstract}

\section{Keywords}

Shared Restaurant, Cloud Computing, Platform Development

\section{Introduction}

Shared economy is a new economic form based on the rapid development of the Internet, which has changed the traditional mode of resource using and business model. Through the sharing of surplus assets between people, the idle resources will be used, so as to enhance economic and social benefits, and thus to recon- 
struct social relations and innovate social system. At present, the shared economy is developing and permeating all walks of life, and has rapidly risen to become the new kinetic energy of leveraging economic and social development. The popularization of open data and mobile Internet provides technical conditions for optimizing the allocation of resources on the shared economic platform. Hunger breeds discontentment; shared economy has very big development space in the catering industry; catering enterprises generally existing information management lags behind, is still difficult to supply chain resources integration and optimization, which caused the restaurants' human technology, food and space resources to waste. And people have higher requirements for dining environment, experience and other aspects. The fierce competition in the catering market will require the catering enterprises to continuously refine the management technology, accumulate the brand value, integrate the resources, and expand the financing channels [1]. The rapid development of various catering $\mathrm{O} 2 \mathrm{O}$ platform models is needed in order to overcome the shortcomings of the traditional restaurant management [2]. The general catering $\mathrm{O} 2 \mathrm{O}$ platform can only achieve online payment and restaurant consumption [3]. They can't share the resources of restaurants, chefs, ingredients, recipes, and can't provide users with a comprehensive daily food and beverage record and provide personalized management and guidance according to the nutritional and healthy status of users, so the stickiness of the system is not enough and it is difficult to analyze and make decisions on the catering of the users [4] [5]. This paper integrates the idea of "shared economy", proposes a shared restaurant business model, and uses cloud computing to integrate and share software and hardware resources and information to build a cloud platform for shared restaurants.

\section{Business Model of Shared Restaurant}

\subsection{Operating Model of Shared Restaurant}

The shared restaurant is joined by a large number of high-end restaurants, campus restaurants, etc., With such restaurants attendance are not high, use the idle space in the restaurant, through the shared platform to integrate the real-time and available resource supply information and demand information of consumer meal, through the big data algorithm accurate matching and connection, achieve mutual benefit between supply side and demand side. Provide shared restaurant brands for franchised restaurants, and provide safe, convenient and affordable catering services for consumers, and create high quality and healthy brand reputation.

Shared restaurant's business and consumer resource information integration is in the shared platform to complete. Franchise restaurant need to upload recipes to the merchant version platform, and to update the available table number and seat, as well as for the sharing of ingredients and other information on the platform. Consumers recharge the platform to become members, and can enjoy coupons and member points and other preferential, and through the platform to 
settle the payment of meal costs. Members input the filter condition on the platform according to the meal demand, such as meal time, number of people, price, taste and other information. Franchise restaurant to look over real-time sharing of ingredients, chefs and other resources on merchant version platform, and buy the rest of the restaurant's leftover ingredients, or rent the chef shared by the shared platform.

The shared restaurant is mainly divided into three different forms, the high-end restaurants, the campus restaurants and the internal guest experience stores, as shown in Figure 1. The high-end restaurants have comfortable restaurant environment, high level of chefs, but because of the high price, there are a lot of idle resources in the restaurant. Members invest in a high-end restaurant, and become a shared restaurant partner, can participate in the management of this high-end restaurant, and share the operating profit of the restaurant. The campus restaurants are usually invested by universities. The restaurants are strictly supervised by food safety, but their professional level and energy consumption are not high, and the tastes are often not as good as the professional restaurant. Shared restaurant provide an opportunity for college students to start businesses. Students invest in a campus restaurant, participate in the restaurant menu development and cuisine hot spot analysis, and share the profits of the campus restaurant. Students with computer technology can participate in the development of shared platform and share the operating profit of the operating company after becoming a partner. The internal guest experience store is invested and operated by the operating company. It is a shared restaurant dedicated to the appointment of important customers and the internal personnel of the operation company. For investment-oriented members or intentions of the restaurants, shared restaurant provide excellent materials, as well as high-end customized tableware experience. Franchise restaurants can buy agri-food base of the famous gifted materials or tableware company's custom tableware, to achieve high-end specialties, tableware sharing. The business model diagram of shared restaurant based on cloud platform is shown in Figure 2.

\subsection{Profit Mode of Shared Restaurant}

First, the shared platform provides shared restaurant brands for restaurants, brings more consumers and higher profits (estimated turnover increased by $20 \%$, profits increased by more than $30 \%$ ), and gains $10 \%$ Commission of shared restaurant turnover. Second, shared restaurant member system attract consumers through coupons and membership points, cultivate users' spending habits, increase users stickiness. Third, for the consumers who are in need of food health, the platform provides experts' diet nutrition analysis and personalized catering service, and collects certain fees on schedule. In addition, shared restaurant platform will push out famous, special, good ingredients in the platform for shared restaurant to buy, as well as its chefs can be rented for share the restaurant, and extract the part of the proceeds. 


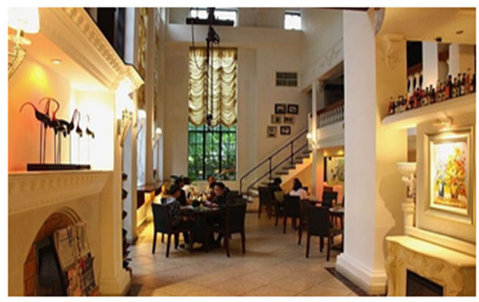

high-end restaurant

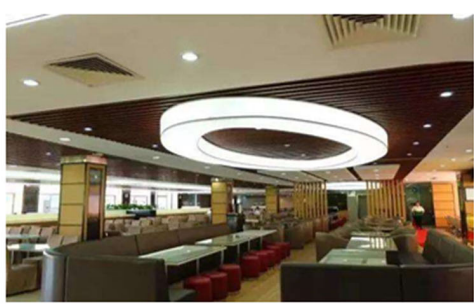

campus restaurant

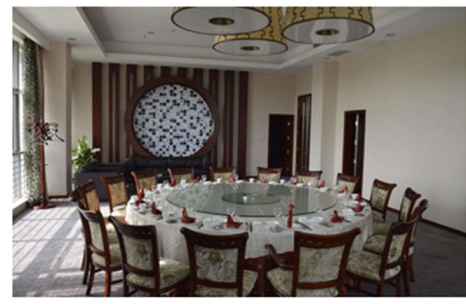

internal guest experience store

Figure 1. Three different forms of shared restaurant.

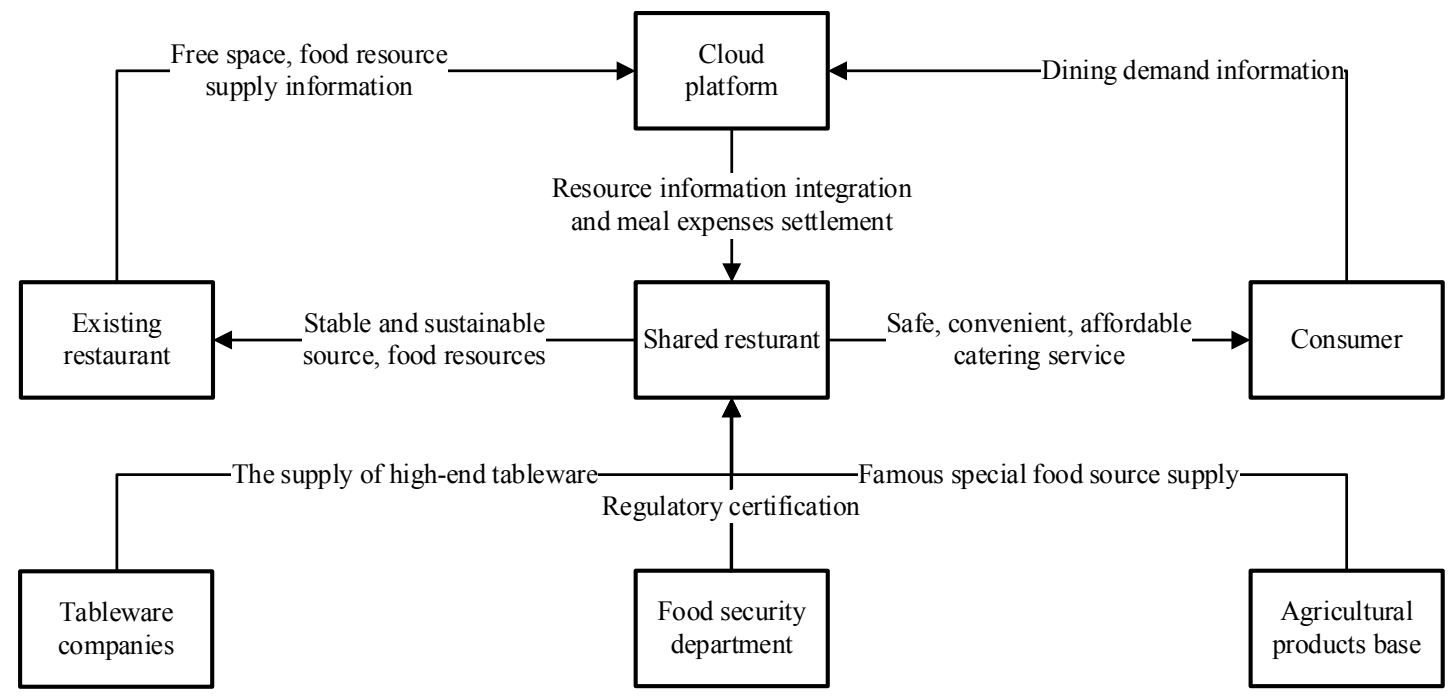

Figure 2. Business model diagram of shared restaurant based on cloud platform.

\subsection{The Advantages of the Business Model of Shared Restaurant}

Shared restaurant, sharing as the core competitiveness; sharing the brand with the franchise restaurants, making the restaurant even as an individual restaurant still enjoy the high-end brand to bring the customer source guarantee. With the promotion of the brand, the franchise restaurants can get more channels of customers, not only limited to the original customers. Through the predetermined function of the platform, manage restaurants more informatively and reduce the table idle rate. For the low idle rate and popular restaurants, if they join the shared restaurant, the brand will provides high-end tourists and enhance consumption, make restaurants increase profits on the basis of the original attendance rate. For consumers, shared restaurants provide consumers with more convenient and secure food and beverage services to meet the needs of personalized and customized catering services. Membership system provides consumers with substitute coupons and member points, make them enjoy more benefits at the expense of shared restaurants. Compared with traditional restaurants, the operation mode of shared restaurant $\mathrm{O} 2 \mathrm{O}$ pays more attention to the integration of online and offline resources, realizes the sharing of free restaurant resources for consumers, and the sharing of idle resources such as food ingredients, chefs and so on for restaurants. 


\section{Architecture and Function Design of Shared Restaurant Platform on Cloud Computing}

\subsection{Shared Restaurant Platform Architecture Based on Cloud Computing}

The overall architecture of the platform is divided into four parts: terminal equipment, service group, data storage and security protection. The terminal consists of two modules, desktop devices and mobile devices. Load balancing service for traffic distribution of multiple cloud servers is implemented by SLB load balancing, and the availability of the application system is improved by eliminating single point of failure. Service cluster deployed by ECS server, realizes flexible computing services, improves operation efficiency, and builds different business modules based on Ali cloud VPC, constructs the complete isolation of the cloud environment [6] [7]. Data storage uses RDS to store structured data, OSS storage pictures and other unstructured data, to achieve massive, safe, low-cost, reliable cloud storage services [8] [9]. Security protection is guaranteed by cloud shield foundation protection, and real-time monitoring of the use of resources by cloud monitoring [10] [11]. The platform overall structure is shown in Figure 3, the terminal equipment as shared restaurant platform directly user oriented interactive interface, receive service requests and large data analysis, and finally feedback to the user results [12] [13] [14].

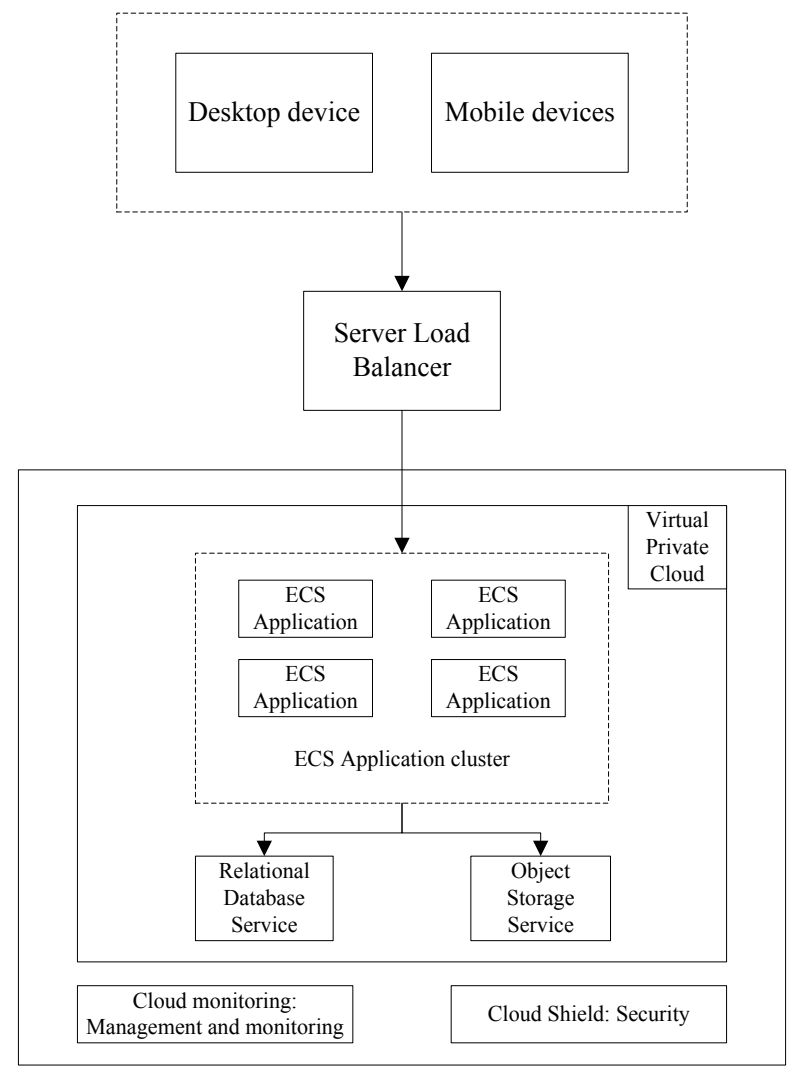

Figure 3. Platform overall structure. 


\subsection{Functional Design of Shared Restaurant Platform}

Application shared restaurant business model is around the platform to achieve, through the sharing of cloud platform (online) integrated restaurants, chefs and ingredients and recipes and other resources, it develops platform members to join and experience shared restaurant (offline), achieves online and offline integration [15]. Therefore, the platform design goal is mainly to meet the restaurant sales demand and the user's ordering requirements, be easy to operate, so that members and restaurants can be efficient and convenient to use the system various functions [16] [17].

Shared restaurant cloud platform mainly contains 3 subsystems, respectively, client, restaurant management background, platform management background.

The overall structure of the platform system function diagram is shown in Figure 4.

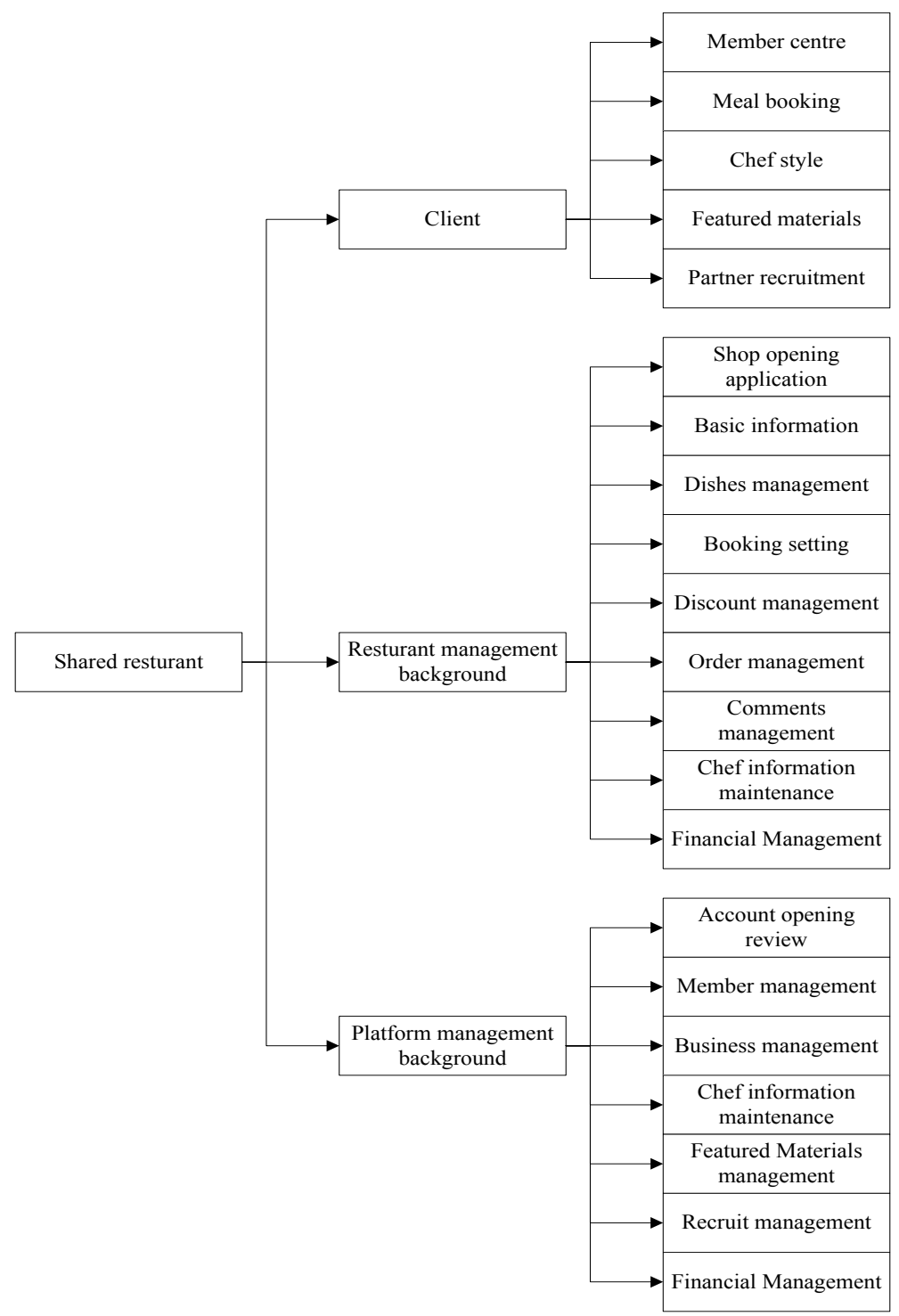

Figure 4. Overall structure diagram of platform system function. 


\subsubsection{Client}

1) Member center module

The member center module is composed of four small modules, and its member information management is shown in Figure 5: the user name, user head portrait, account balance, integral, membership level are displayed on the page. Users can enter personal information module, set up and modify their own information, including login information and personal information. Users can enter the order management module, check all orders, and evaluate the orders which are not evaluated, such as dishes, restaurants evaluation. Users can enter the collection management module, view and modify the personal collection of restaurants, ingredients, recipes, chef list. The user can enter the personal account module, the user can use WeChat, Alipay and other prepaid accounts to recharge, account balance can be used to consume on the platform, have coupon and integral, including the rules of coupon use, the amount of discount coupons, period of using. History accumulated integral (used to judge the user's membership level), and can redeem coupons with membership integral. The relevant interface of the APP is shown in Figure 6.

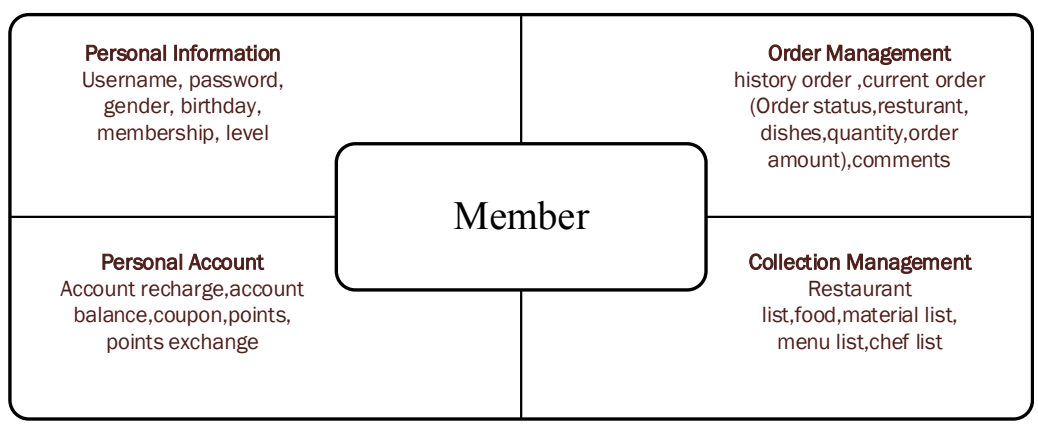

Figure 5. Member information.

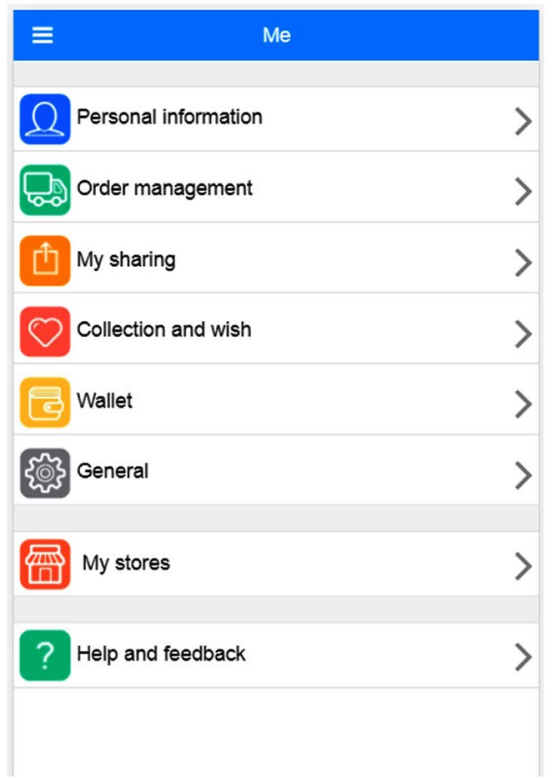

Figure 6. Interface of the APP. 
2) Meal booking module

Online meal booking service is implemented, including restaurant selection, date and time booking, room selection, dishes selection, online payment. Users have two ways to choose, one is booking meal, two is outgoing meal. Meal booking process: the user enters the restaurant list page to select the restaurant, then chooses whether to order a meal or deliver a meal. If you choose to book order meal, then it will jump to the relevant page for to order the meal time, number of people, room number, dishes, and fill in the user contact information; If you choose outgoing meal, then it will jump to the relevant page for user to choose dishes, and fill in the contact, delivery time, address, as shown in Figure 7. After the completion of the meal ordering, the system will automatically generate orders and calculate the amount of payment, the user clicks to confirm payment, complete payment.

3) Chef style module

On chef style page, the platform will show the popular chef information, including the chef picture, name, and a brief introduction. Choose the chef process as shown in Figure 8: When the users enter the chef style page, you will see the chef list on the platform. Users can click on their favorite chef and have a detailed understanding of the chef, including the chef's detailed personal information, restaurant information, and the characteristic dishes of the chef. You can select the chef after the understanding is completed, and click to enter the chef's restaurant ordered meal page, complete the meal.

4) Featured materials module

Featured materials module has two small modules, classified materials, popular materials recommendation. Featured materials module will be divided into 5 categories of poultry meat, aquatic products, vegetables, fruits, grain oil category, popular materials recommendation module will display daily, weekly, monthly popular materials recommendation. The user can choose the specific materials to know about details, including materials sources, processing, nutrition, efficacy, price and other information. In the full understanding of the materials, the users can purchase required materials on online, or make an appointment to the restaurant to ask the chef to cook dish, then enjoy eating.

5) Partner recruitment module

\begin{tabular}{|c|c|}
\hline booking meal & outgoing meal \\
\hline meal time, number of people, & delivery time \\
room number, dishes, & Address dishes \\
fill in the contact information & fill in the contact information \\
\hline
\end{tabular}

Figure 7. Booking information.

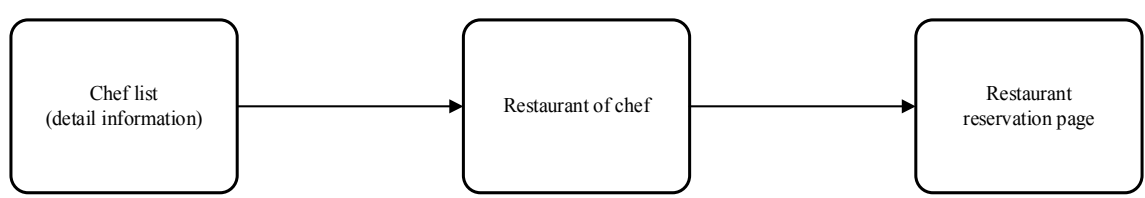

Figure 8. Choose the chef process. 
In the partner recruitment page, the information of partner recruitment will be displayed in graphic form, including the recruitment conditions of partners, the responsibilities and rights of partners enjoy; the reward policies of the platform to partners, and the relevant recruitment procedures. If the users of the platform have the intention to join, they can fill in the corresponding application and submit it to the platform administrator for verification. After the audit is successful, the users can identify the contract with the platform and become a platform partner.

\subsubsection{Restaurant Management Background}

1) Shop opening application and basic information module

Shop opening application module is designed for restaurants, users enter the application page, submit the identity certificate and business license, and fill in the shop address, contact information, transfer methods. Determine the commission after the administrator audits.

Basic information module is divided into basic restaurant information (address, size, main food and beverage content, license, etc.), restaurant chef information, restaurant dishes information, restaurant table information and other small modules. Restaurants can view, add, delete, and modify the basic information of restaurants in real time.

2) Dishes management module

Dishes management module includes the two small modules, Information management, dishes classification. The restaurants can view, add, delete, modify the menu information, classified management of new dishes, such as home cooking, soup, vegetable dish, meat dish, etc. Shop administrator adds menu information as shown in Figure 9 include: the basic information of dishes (dishes name, type, price, introduction, cover image, hot dishes, discount information), detailed information (such as materials of food, name, amount, sources, cooking steps, dishes nutrition and efficacy).

3) Booking setting module

The restaurant administrators need to maintain the booking information of the booking page for the client. Set the date and time period of the restaurant which can be scheduled, room number, set the number of guests (such as $5-8$, more than 8 people) who can choose a room, the minimum consumption of different number of people for the user to choose. Such as restaurants set up 18:00 20:00 in September 21, 2017, room 1. The number of diners can choose $5-8$ people, 8 - 10 people, more than 10 people. The minimum amount of consumption corresponding to the number of people is $500,800,1000$. The booking data relation is shown in Figure 10.

4) Discount management module

Restaurants can set up discount information, including discount activity time, discount rules, discount object restrictions, consumption integral calculation methods, coupons distribution methods and other settings. The discount rules are mainly filled down rules, which are defined by restaurants. 


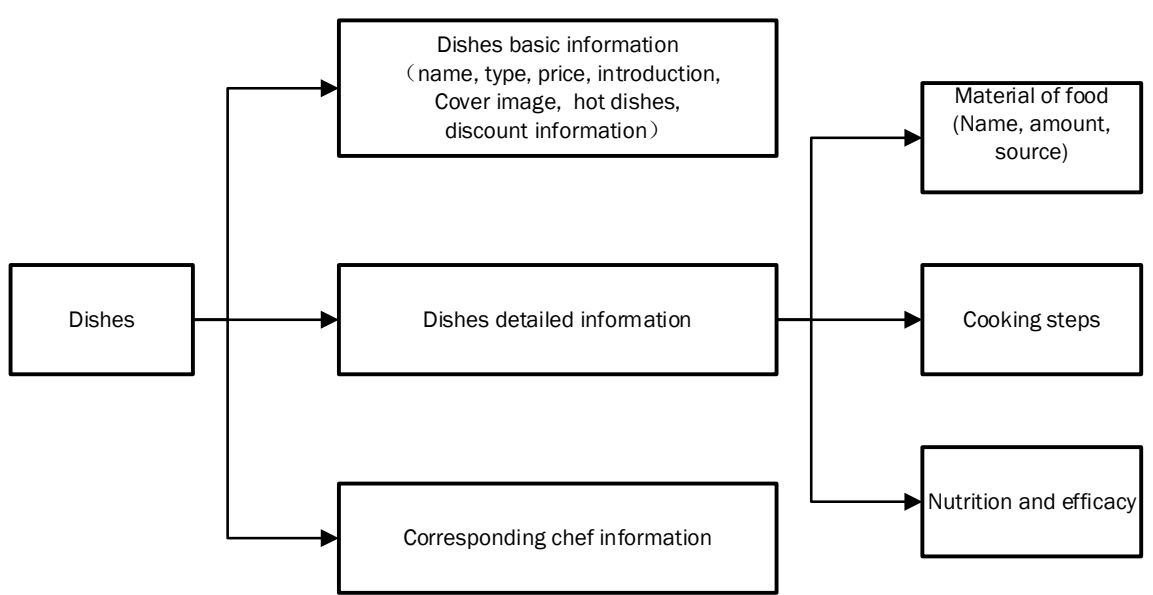

Figure 9. Dishes information.

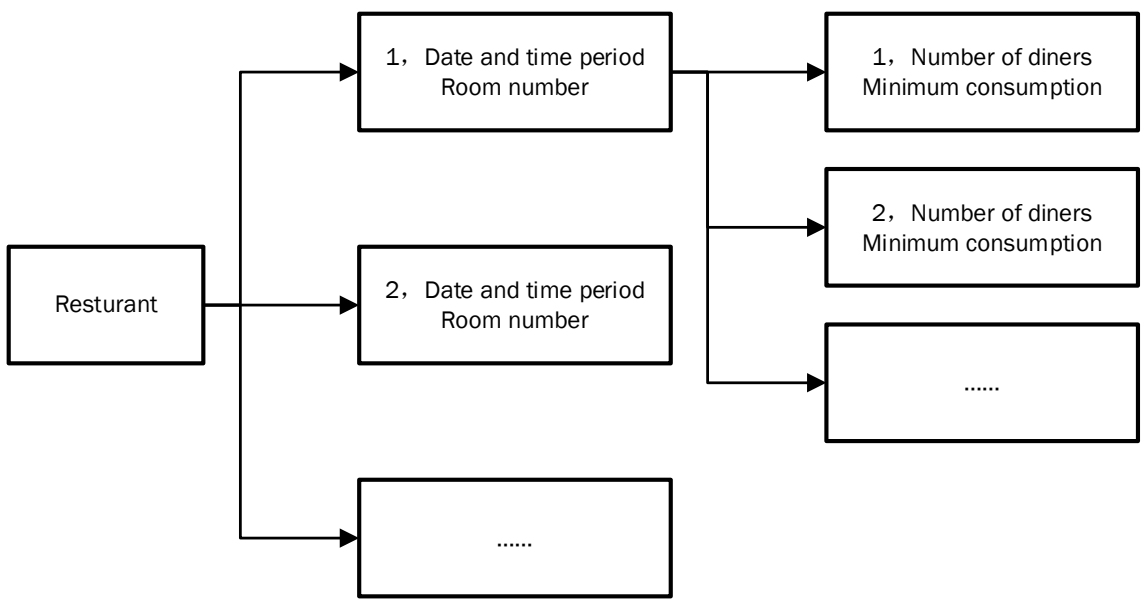

Figure 10. Booking data relation graph.

5) Order management module

In the merchant background order management page, the merchant administrator can look over the information of the new order; the order is divided into the booking order and the outgoing order. According to the user's behavior, the order status is processed synchronously, and the order status is modified. For example, the user completes the booking dishes and online payment, and the user completes the meal at the restaurant, and the status is "paid" and "consumed". For outgoing meal, correspondingly, set the "orders received" and “served" status.

6) Comments management module

The merchants receive the user's comments and feedback information on the platform, and give sincere thanks to the users' good comments, or patiently explained poor comments for users. If it is indeed the fault of the restaurant, the restaurant should give users a certain discount. For some malicious comments feedback, the restaurant can report, and information can be deleted after verification by the platform administrator. 
7) Chef style information maintenance module

Restaurants can add, modify, and delete chef information. Chef information, including chef name, personal resume, chef's characteristics of dishes. Chef and restaurant dishes, cooks and dishes have a corresponding relationship. Restaurants and cooks are one-to-many relationship, cooks and dishes are one-to-many relationship.

\subsubsection{Platform Management Background}

1) Account opening review module

After receiving the account opening application, the platform administrator needs to strictly examine and audit the information submitted by the restaurants. If the information is verified correctly, the platform administrator should take the initiative to conduct online negotiation with the restaurants, emphasize the important information after the restaurant enters the platform. After merchants agree, they can enter the platform and their business information is inputted into the background system.

2) Member management module

The platform administrators need to be responsible for the members of the platform, and the administrators need to audit and manage the membership information to ensure the safety and reliability of the member's personal information, protect the privacy of the members, and prevent the information leakage. Administrators can view, add, delete, modify member information, reflect the behavior of members in a timely manner.

3) Business management module

Business management module includes restaurant classifying, restaurant managing information and restaurant administrator information. The restaurants are divided into large, medium and small restaurants, and platform puts forward different requirements for different scale restaurants, different financial management. Timely reflect the information modified by the restaurants themselves, synchronously modify and update the restaurants, restaurant administrators information, prompt services for the expired business contract expires, delete the restaurant of non-renewal.

4) Chef information maintenance module

Platform administrator should add, delete, modify chef information according to restaurant behavior, timely manage and maintain chef information, and the real-time modified chef information is sent back to the client of the platform synchronously through the server for the members to view, select and make booking.

5) Featured materials management module

According to the information provided by the restaurants, the platform administrator can classify and manage the special materials, collect and manage the popular materials such as daily, weekly and monthly hot material, timely process the information of the materials modified or added by the restaurants through the server, and synchronously feedback to the platform client for users to buy, 
book.

6) Recruitment information maintenance module

The platform administrator can continuously update and perfect the information about partner recruitment according to the change of national policy and market demand, such as the recruitment conditions of partners, the responsibilities and rights enjoyed by partners, the platform reward policies of partners and the related recruitment procedures and other information to attract more partners.

\section{Conclusion}

In order to meet the restaurant sales demand and the users' ordering requirements, so that members and restaurants can be efficient and convenient to operate, this paper provides a shared restaurant platform based on cloud computing, and integrates the idea of "sharing economy" to propose a shared restaurant business model, including the shared restaurants operating model, profit mode, and the advantages of the business model. The platform technology architecture is developed by using the characteristics and advantages of cloud computing, including four parts of terminal equipment, service group, data storage and security protection. Finally, design the detailed function modules of the system and the flow chart of the specific function modules. This research is aimed at solving the existing restaurant management defects, further integrating and optimizing the food and beverage supply chain resources. We use three function subsystems of client, restaurants management background, and platform management background to build shared restaurant platform system. Make full use of shared resources (empty tables, chefs, ingredients, recipes, etc.) on the Internet, and develop platform members to join and experience shared restaurant (offline), and truly achieve $\mathrm{O} 2 \mathrm{O}$ (online and offline) integration, achieve food culture and wealth investment integration (tasting the added wealth of food). This paper puts forward the concept model of shared restaurant. Through cloud computing technology, related businesses in the takeaway industry chain, such as food and beverage raw material producers, suppliers and catering service providers, are brought into the new ecological cooperation model to form a new ecosystem.

\section{Conflicts of Interest}

The author declares no conflicts of interest regarding the publication of this paper.

\section{References}

[1] Hai, N., Ganapathy, V., Srivastava, A., et al. (2016) Exploring Infrastructure Support for App-Based Services on Cloud Platforms. Journal of Computers \& Security, 62, 177-192. https://doi.org/10.1016/j.cose.2016.07.009

[2] Hou, F. and Mao, X.J. (2016) Cross-Clouds Services Autonomic Management Approach Based on Self-Organizing Multi-Agent Technology. Journal of Concurrency \& Computation Practice \& Experience, 28, 3213-3237. https://doi.org/10.1002/cpe.3760 
[3] Gardner, C.D., Whitsel, L.P., Thorndike, A.N., et al. (2014) Food-and-Beverage Environment and Procurement Policies for Healthier Work Environments. Journal of Nutrition Reviews, 72, 390. https://doi.org/10.1111/nure.12116

[4] Wu, T.J., Zhao, R.H. and Tzeng, S.Y. (2015) An Empirical Research of Consumer Adoption Behavior on Catering Transformation to Mobile O2O. Journal of Interdisciplinary Mathematics, 18, 769-788. https://doi.org/10.1080/09720502.2015.1108088

[5] Barton, T.L. and Macarthur, J.B. (2016) A Teaching Case on the Benefits and Costs of Restaurants Using Opentable Online Restaurant Reservations. Journal of Business \& Accounting, 9, 126.

[6] Chang, V., Kuo, Y.H. and Ramachandran, M. (2016) Cloud Computing Adoption Framework: A Security Framework for Business Clouds. Journal of Future Generation Computer Systems, 57, 24-41. https://doi.org/10.1016/j.future.2015.09.031

[7] Sen, J. (2016) Security and Privacy Issues in Cloud Computing. International Journal of Grid \& Distributed Computing, 7, 238-252.

[8] Fu, C. (2015) Development of Network Cloud Storage System Based on Android Platform. Journal of Communication World, No. 21, 239-240.

[9] Zhang, J.L., Wang, J., Lv, X.S. and Han, Y.P. (2014) Design of Health Monitoring Platform Base on Medical Wisdom. Journal of Applied Mechanics \& Materials, 644-650, 1062-1065. https://doi.org/10.4028/www.scientific.net/AMM.644-650.1062

[10] Xie, X.L., Liu, C.Y. and Liu, R.K. (2014) Research and Design of Cloud-Based Campus-Plus System on Android Platform. Journal of Applied Mechanics \& Materials, 556-562, 5518-5522.

https://doi.org/10.4028/www.scientific.net/AMM.556-562.5518

[11] Sun, S., Cegielski, C.G. and Li, Z. (2015) Research Note for Amassing and Analyzing Customer Data in the Age of Big Data: A Case Study of Haier's Online-to-Offline (O2O) Business Model. Journal of Information Technology Case \& Application Research, 17, 156-165. https://doi.org/10.1080/15228053.2015.1095017

[12] Wen, M.Y. (2017) Design and Implementation of Online Ordering System Based on Service. Journal of Jiamusi Vocational Institute.

[13] Ali, A., Warren, D. and Mathiassen, L. (2017) Cloud-Based Business Services Innovation: A Risk Management Model. International Journal of Information Management, 37, 639-649. https://doi.org/10.1016/j.ijinfomgt.2017.05.008

[14] Khan, A.N., Kiah, M.L. M., Ali, M., Shamshirband, S. and Khan, A.U.R. (2015) A Cloud-Manager-Based Re-Encryption Scheme for Mobile Users in Cloud Environment: A Hybrid Approach. Journal of Grid Computing, 13, 651-675. https://doi.org/10.1007/s10723-015-9352-9

[15] Caputo, P., Clementi, M., Ducoli, C., Corsi, S. and Scudo, G. (2017) Food Chain Evaluator, a Tool for Analyzing the Impacts and Designing Scenarios for the Institutional Catering in Lombardy (Italy). Journal of Cleaner Production, 140, 1014-1026. https://doi.org/10.1016/j.jclepro.2016.06.084

[16] Piao, C.H., Zuo, Y. and Zhang, C.Y. (2016) Research on Hybrid-Cloud-Based User Privacy Protection of O2O Platform. 2016 IEEE 13th International Conference on e-Business Engineering (ICEBE), Macau, 4-6 November 2016, 214-219.

[17] Zhi-Jun, L.I., Tang, S.R., Guang-Wen, L.I., Pharmacy, F.O. and University, F.M. (2016) Exploration on Construction of Online-Booking and Sharing Platform for Large-Scale Instruments and Equipment. Strait Pharmaceutical Journal, 28, 279-281. 